\title{
A world without Greenland: impacts on the Northern Hemisphere winter circulation in low- and high-resolution models
}

Received: 27 February 2004/ Accepted: 5 November 2004/Published online: 18 January 2005

(C) Springer-Verlag 2005

\begin{abstract}
To investigate the effect of Greenland's orography on the northern hemisphere winter circulation experiments with an atmospheric GCM are conducted: a perturbed integration where standard orography is reduced to sea level in the Greenland area is compared to a standard orography control integration. The outcome of these experiments suggests that the existence of high mountains at Greenland causes a reinforcement of the stationary wave field in the Atlantic sector, colder temperatures to the west of Greenland and warmer temperatures to the east and south, over the North Atlantic. The impact on the flow field cannot be understood in the framework of standing Rossby waves, but it indicates a resonance between remotely forced stationary waves and local (thermo-) dynamics. The pattern of the North Atlantic Oscillation (NAO), in particular the northern centre, lies further to the east in the flat-Greenland experiment compared to the control run and the observations. Together with the fact that the climatological low-pressure system around Iceland hardly shifts, this suggests that the location of the NAO is not necessarily tied to the time mean pressure distributions. Considering the model resolution as a parameter, experiments with a high resolution (T106) suggest that the near-field changes are represented sufficiently by a T42 resolution, a standard resolution used in state-of-the-art coupled climate models. In contrast, far-field changes depend critically on model resolution. Hemispheric circulation and temperature
\end{abstract}

M. M. Junge $(\bowtie) \cdot R$. Blender $\cdot$ K. Fraedrich

U. Luksch · F. Lunkeit

Meteorologisches Institut, Universität Hamburg,

Hamburg, Germany

E-mail: junge@dkrz.de

Tel.: + 49-40-428385069

Fax: + 49-40-428385066

V. Gayler

Modelle und Daten am Max-Planck-Institut für Meteorologie, Hamburg Bundesstrasse 55, 20146 Hamburg, Germany changes differ substantially from low to high resolution, and generalized statements about the impact of Greenland's orography cannot be made.

\section{Introduction}

Greenland with its glacier mountains constitutes the third largest topographic feature on the northern hemisphere, with respect to its height and extension. It reaches maximum heights of over $3,500 \mathrm{~m}$ and stretches over $2,600 \mathrm{~km}$ meridionally and $1,000 \mathrm{~km}$ zonally at about $70^{\circ} \mathrm{N}$. The southern tip, however, is a narrow, albeit high appendix.

The topographic forcing exerted by the geographical obstacle Greenland on the atmospheric flow field has mainly been thought to be relevant to synoptic systems (Kristjánsson and McInnes 1999) and the storm track. Schwierz (2001) has shown that the path of individual systems across the North Atlantic is shaped by the presence of this orographic feature. Many studies state a connection of the North Atlantic storm-track path and intensity with the high-/low- index phase of the North Atlantic Oscillation (NAO), the main mode of variability in the North Atlantic region. A high NAO index is associated with stronger mean winds and-on average - a more northeasterly path of the synoptic systems (for example Lau 1988). One centre of action of the NAO occupies the region in the wake of Greenland. The role of the Greenland glacier mountain in determining this particular location has not been discussed so far.

"Orographic forcing" of the large-scale atmospheric circulation has a longstanding history in dynamical meteorology: from Charney and Eliassen (1949), who were the first to show that, to first-order approximation, the quasi-stationary wave pattern along $45^{\circ} \mathrm{N}$ can be accounted for as the forced wave response to large-scale orography (i.e. the Rocky Mountains and the Tibetan 
Plateau), to the very recent ignition of the discussion by Seager et al. (2002) who claim that ultimately orographic forcing of stationary waves in the wake of the Rocky Mountains is responsible for the sharp climate contrast between European and North American winters. With the advent of atmospheric general circulation models (GCMs), quantitative tests of the impact of diabatic and mechanical forcing of the principal low- and high-pressure systems in middle latitudes were possible. Held (1983) concluded that the Icelandic low is partly forced thermally, but that the Rocky Mountains and the Tibetan Plateau force a wavenumber two stationary wave. Early models were still relatively coarse in their resolution, so an impact of Greenland could not be expected, and-due to the experimental set-up - could not be isolated.

Considering "polar orographic forcing", scaling arguments preclude the Greenland glacier mountain to be of any relevance as mechanical forcing of stationary waves (Kristjánsson and McInnes 1999). Greenland is different from the Rocky Mountains and the Tibetan Plateau (1) for its polar location (between $60^{\circ} \mathrm{N}$ and $80^{\circ} \mathrm{N}$ ) at latitudes of small Rossby-radii and (2) for being situated in a region of mostly easterly low-level flow, except at the southern tip. Thus, with Rossby waves propagating westward, stationary waves do not seem possible. However, Ringler and Cook (1995) show that even a polar mountain with ambient easterly lowlevel flow but westerly flow above can instigate a hemispheric wave response. Moreover, if the assumption of a uniform zonal flow, widely used in quasi-geostrophic perturbation theory, is dropped, the relevant parameter becomes $\beta^{*}=\beta-U_{y y}$, with $\beta$ the meridional gradient of planetary vorticity and $U$ the zonal flow. The Rossby wave paths, then approximately, follow a great circle (Hoskins and Karoly 1981). More recently, Schwierz (2001) meticulously investigated the various ways in which Greenland can affect dynamic systems and stated that there is a role for Greenland in the large-scale circulation. This is corroborated by a recent study by Petersen et al. (2004), who find a significant impact on the general circulation of the extra tropical northern hemisphere in both the lower and middle troposphere.

Model resolution is a critical quantity when discussing effects of relatively small-scale forcing. Various studies show that the experimental results depend substantially on model resolution. Dong and Valdes (2000) investigated changes from the Last Glacial Maximum to Present Day conditions: the results of an AGCM truncated at total wave number 21 (T21) were qualitatively different from those obtained from T42 and T63, some times even contradictory. The difference between the latter two integrations proved rather quantitative than qualitative, and they were consistent with paleoclimate data. Merkel and Latif (2002) later showed that T106 resolution is important to model eddy dynamics and the associated heat transport in the storm-track regions. Taking the findings of Dong and Valdes (2000) and Merkel and Latif (2002) into account, the following array of GCM experiments is set-up: for two different resolutions, namely $\mathrm{T} 42$ and $\mathrm{T} 106$, of the same atmospheric model, control and perturbation experiments are integrated. The difference between control and perturbed experiments is essentially the height of orography over the Greenland area. With this set-up, we hope to elucidate some of the near-field and far-field responses of the model to the altered orography and also obtain an indication of the reliability of the results with respect to model resolution. The results show consistent near-field changes from control to perturbed experiments that are independent of model resolution. Both resolutions also give significant far-field changes, which are, however, qualitatively different. The remainder of this paper is organized as follows. Section 2 briefly explains the model and experiment set up. Section 3 contains the effects on stationary waves and associated climatic changes. Teleconnections and storm tracks are discussed in Sect. 4, after which Sect. 5 presents a synthesis and partial interpretation of the results.

\section{Experiments}

The model used in this investigation is ECHAM4 (Roeckner et al. 1996) in two resolutions, T42 and T106, with 19 vertical layers. For each resolution, two integrations are performed, that is, a control integration (CTRL) and a perturbed integration (NOGREEN). For the latter, the orography is set to zero at all grid points representing the model Greenland, with initial condition fields adjusted to the new geography.

To understand the difference in model resolution, Fig. 1 shows the orography for the two resolutions that were used. The height maximum in the centre of
Fig. 1 Topographic height in the Greenland area $\left(80^{\circ} \mathrm{W}-\right.$ $\left.30^{\circ} \mathrm{W}, 55^{\circ} \mathrm{N}-85^{\circ} \mathrm{N}\right)$ : a $\mathrm{T} 42$ resolution, b $\mathrm{T} 106$ resolution; Contour interval $500 \mathrm{~m}$
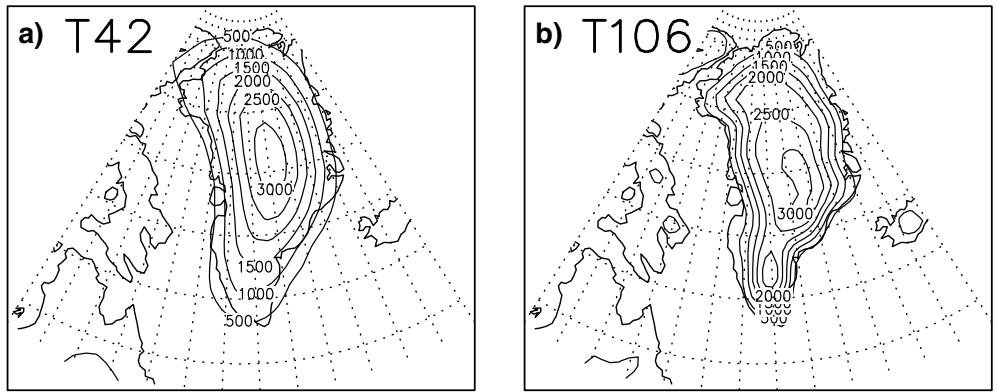
Greenland is captured in both, high and low resolution, but the gradients are considerably sharper in the T106 resolution. In the latter, the secondary maximum at the southern tip is present, whereas it is absent in the T42 version.

For all experiments, the model is forced with climatological sea surface temperatures (SSTs). Integration years available for the lower (T42) resolution are 20 and for the higher (T106) 27. In this paper, we restrict our attention to the winter season (DecemberJanuary-February: DJF), but time mean changes for summer have also been analyzed and show qualitatively similar results. The changes that are displayed in the figures (NOGREEN-CTRL) represent the effect of Greenland orography being removed rather than the effect of orography being introduced (which may be a more familiar perspective from idealized model experiments for some readers). For the difference in climatological means, a $t$-test is applied, with figures illustrating the risk of rejecting the null hypothesis of the means being equal while it is true at 0.05 (dark shading) and 0.1 (light shading). As we use winter data only from integrations with climatological SST forcing, i.e. the same forcing for every winter, the 19 and 26 winter realizations, respectively, are assumed to be independent realizations.

The ECHAM4 model has been used for a multitude of investigations in both resolutions, in control runs, model intercomparison projects and coupled models, where many of the model characteristics and deficiencies have been investigated and discussed at length (May 2001; Bacher et al. 1998; Christoph et al. 2000; Ulbrich and Christoph 1999). Particular aspects of the climatology are discussed here only in those cases where it seems important for an understanding of the responses.

One such field is sea level pressure (SLP). In particular, the performance in the northern North Atlantic region deserves a closer look. The panels in Fig. 2 display climatological sea level pressure as derived from the ERA15 dataset (Fig. 2a) and the results of the two control integrations (Fig. 2b, c). The observations show the familiar dipolar structure in the North Atlantic region, with low pressure in the northern region, centred between the South Greenland tip and Iceland, and the subtropical high-pressure band with maxima encompassing the Azores Islands. This structure is reproduced qualitatively in the low-resolution model, but not in the high-resolution model. In the latter, the low-pressure system is expanded considerably to the northeast, with lowest values occurring in the region between northern Greenland and Norway. This model deficiency in the high-resolution case has been documented (see May 2001 , for example). However, the reason of it arising in the high rather than the low-resolution model has not been fully understood.
Fig. 2 Sea level pressure climatology in DecemberJanuary-February (DJF): a ERA15, b T42 CTRL, and c T106 CTRL; Contour interval $5 \mathrm{hPa}$, thick line $1,000 \mathrm{hPa}$

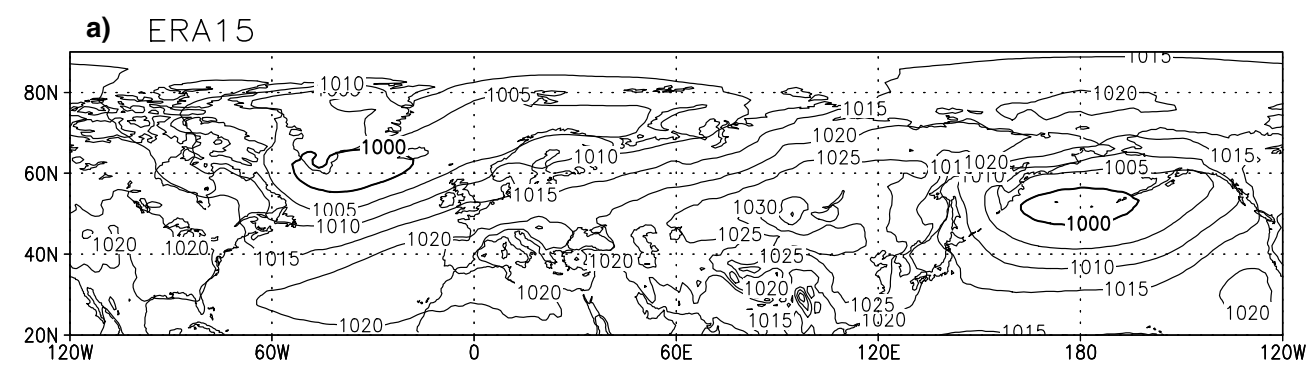

b) $\mathrm{T} 42$

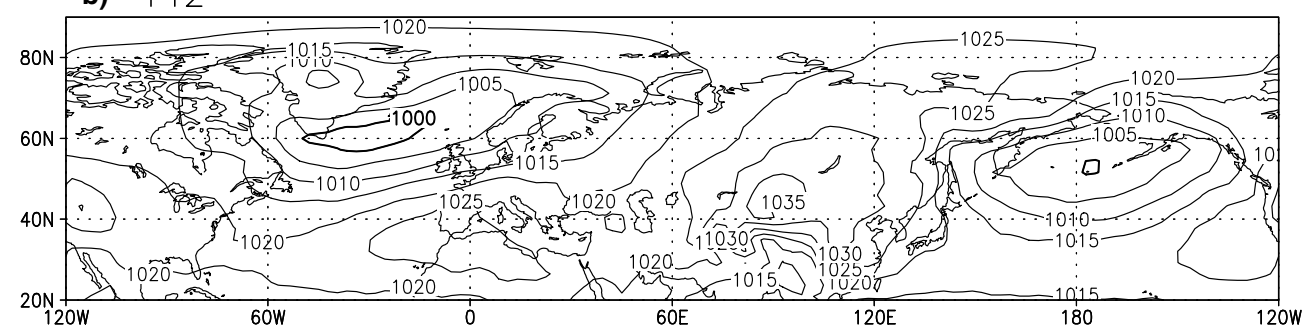

c) $\mathrm{T} 106$

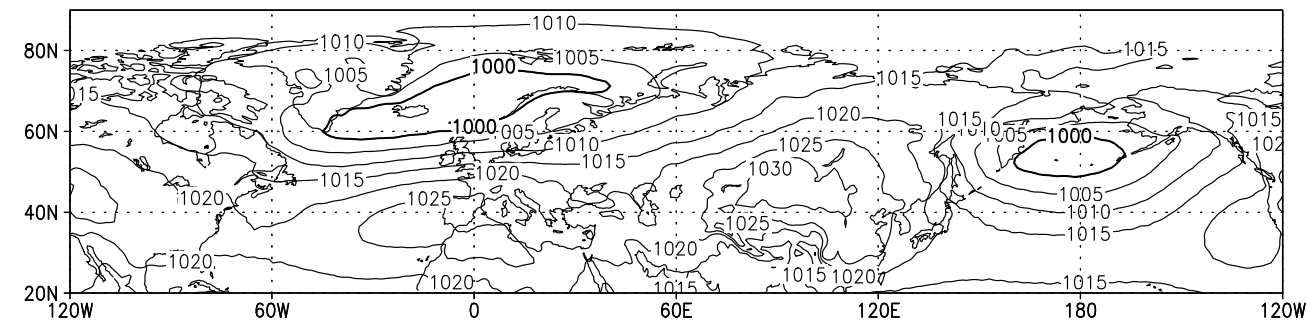




\section{Stationary waves and climate response}

Do we see an impact on the stationary wave field in the model experiments?

A standard representation of the stationary wave field is the deviation of the $500 \mathrm{hPa}$ geopotential height from its zonal mean. The climatology of this field for both CTRL integrations is presented in Fig. 3, together with the same quantity derived from the ERA15 dataset. The structure of wavenumber two is modelled in both resolutions, with the centres of the troughs in the wake of the major mountain chains and the ridges about in the right geographical location. Magnitudes are comparable to observations, though the trough over eastern Canada is somewhat weaker in both experiments, while the ridge over the eastern North Atlantic is stronger, in particular, in the T106 resolution. One apparent difference shows up in the poleward extension of the ridge over the Rocky mountains: in the ERA15 dataset, this ridge extends almost to the North Pole, whereas in the model integrations, its confinement lies further south.

Plumb (1985) argues from the analysis of the waveactivity flux (a conservation relation for quasi-geostrophic stationary waves on a zonal flow, which permits a local analysis of propagation of wave activity in a three-dimensional circulation) that the source of stationary wave activity in the western Atlantic is thermal rather than orographic. In his view, the Rockies play a minor role as forcing of the stationary eddies in this region. The same appears to be true in the model. In both integrations, the diagnosed wave-activity flux indicates that two distinctive wave trains are spreading upward and eastward/equatorward from eastern North America, originating rather over the ocean and the east coast than over the Rocky Mountains (not shown).

Changes in the stationary wave field from the CTRL to NOGREEN experiments are illustrated in Fig. 4. They are considered as the superposition of (a) a local and (b) a hemispheric or far-field response and will be discussed separately in the following.

\subsection{Local response}

For both resolutions, a dipolar structure over the Canadian/North Atlantic sector clearly emerges. A decrease of up to $60 \mathrm{~m}$ between Greenland and Norway is accompanied by an increase of the same order of magnitude over northeastern Canada and Baffin Bay. The positive anomaly over northeastern Canada lies in the northern parts of the climatological trough in the wake of the Rocky Mountains, but has opposite sign. This means that the trough is much weaker in the experiment without Greenland. In other words, the Greenland orography reinforces this trough. The same can be said for changes of the climatological ridge in the East Atlantic. With a flat Greenland this ridge is weakened,
Fig. 3 Zonally asymmetric component of $500 \mathrm{hPa}$ geopotential height in DJF north of $20^{\circ} \mathrm{N}$ : a ERA $15, \mathbf{b}$ T42 CONTROL, and c T106 CONTROL; Contour interval $50 \mathrm{~m}$

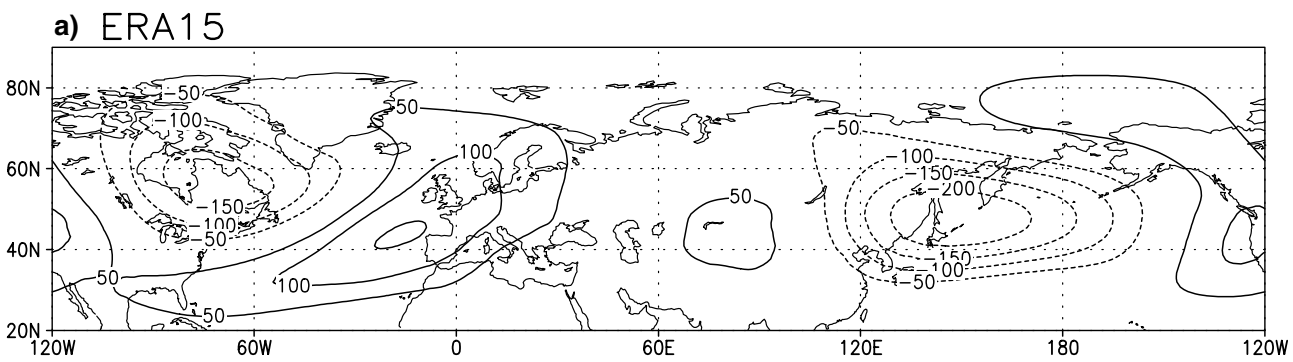

b) $\mathrm{T} 42$

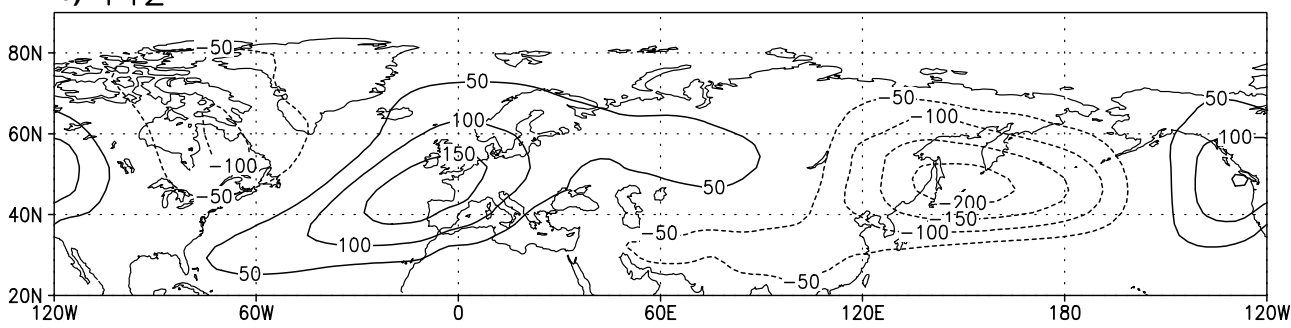

c) $T 106$

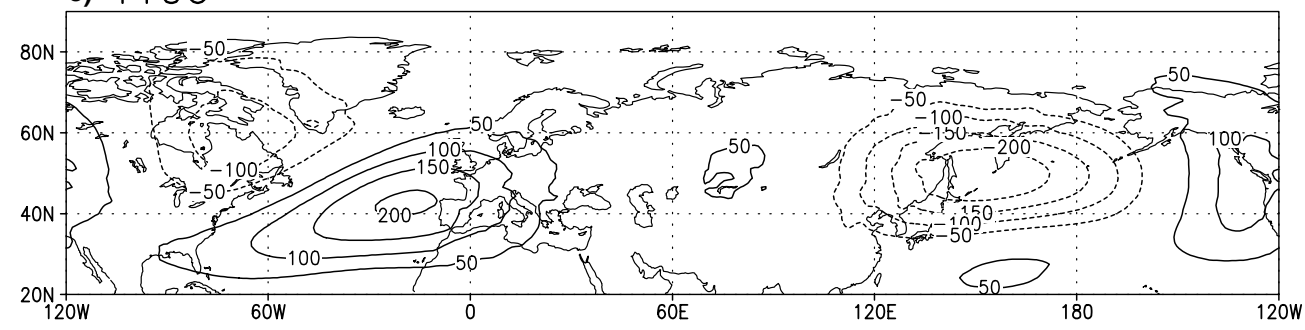


Fig. 4 Change in zonally asymmetric component of $500 \mathrm{hPa}$ geopotential height in DJF from CTRL to NOGREEN integration: a T42, b T106; Contour interval $10 \mathrm{~m}$, no zero line drawn. Dark shading 0.05 significance level, light shading 0.1 significance level. Positive values denote greater heights in the NOGREEN integration a) T42 Z500* NOGREEN-CTRL

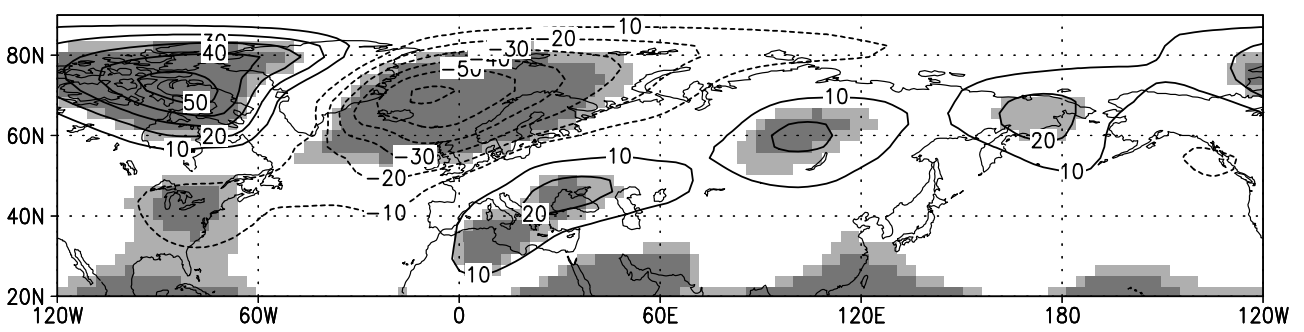

b) T106 Z500* NOGREEN-CTRL

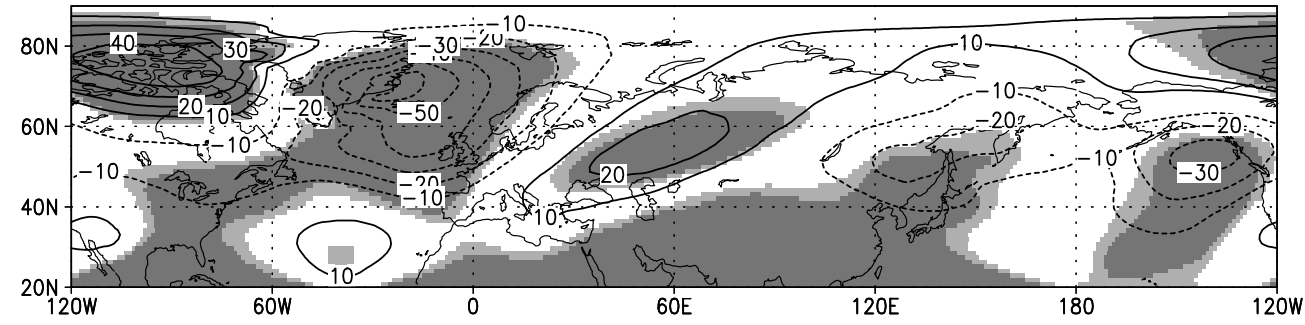

mostly in its northern parts. Together, the effect is that the stationary wave field in the Atlantic sector is weaker in a flat-Greenland world. This is corroborated by the changes in the wave-activity flux in this region. Both resolutions consistently indicate reduced southwesterly wave flux over the entire Canadian area (not shown). That is, with a flat Greenland, the wave flux is more zonally oriented and weakened. This result is independent of the model resolution. The changes we see in the geopotential height field are mainly attributable to changes in the $500-1000 \mathrm{hPa}$ layer thickness. The strongest SLP changes occur over central Greenland and display a dipolar characteristic in the T42 resolution, but a monopolar structure with reduced SLP in the T106 resolution (not shown). In this area, alterations of the stationary wave field at $500 \mathrm{hPa}$ are negligible. In parts of the Nordic seas, negative SLP changes between $2 \mathrm{hPa}$ and $4 \mathrm{hPa}$ occur in both model resolutions.

The local, dipolar response in the geopotential height field does not possess the characteristics of stationary

\section{a) $\mathrm{T} 42 \mathrm{~T}$ on $500 \mathrm{hPa}$}

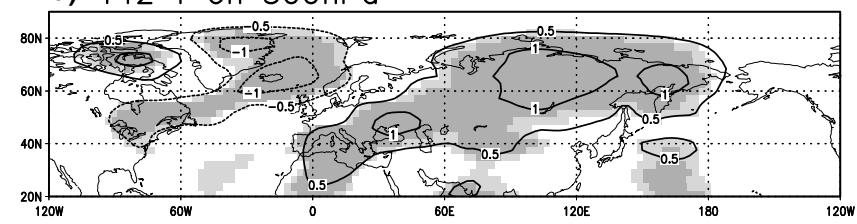

c) $\mathrm{T} 42 \mathrm{~T}$ on $1000 \mathrm{hPa}$

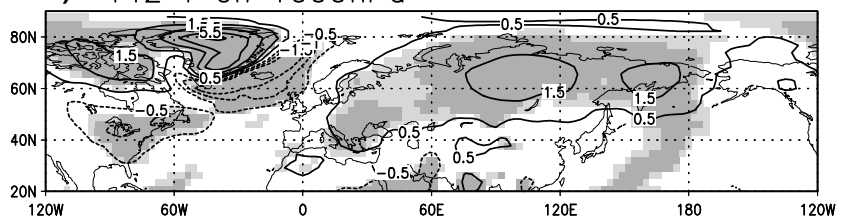

Fig. 5 Temperature changes from CTRL to NOGREEN experiment at $500 \mathrm{hPa}(\mathbf{a}, \mathbf{b})$ and $1000 \mathrm{hPa}(\mathbf{c}, \mathbf{d})$ : $(\mathbf{a}, \mathbf{c}) \mathrm{T} 42$ resolution, and $(\mathbf{b}, \mathbf{d})$ T106 resolution; Contour intervals in $(\mathbf{a}, \mathbf{b}) 0.5 \mathrm{~K}$, no zero
Rossby waves (in westerly flow), i.e. a ridge over the elevated orography and a trough downstream. Instead, the ridge constitutes downstream of the mountain and the trough upstream. A possible explanation would be that in the CTRL experiment, low-level flow to the west of Greenland is blocked by the mountain, and in winter, cooled persistently by the cold land surface and sea ice. This would account for the lower layer thicknesses and hence, lower geopotential heights than in the NOGREEN case.

Indeed, throughout the lower and middle troposphere, we find warmer temperatures upstream over eastern Canada in the case of Greenland being flat land (Fig. 5). This holds for both resolutions. At the same time, the negative temperature anomalies over a slanting band from central North America at about $50^{\circ} \mathrm{N}$ to the Nordic seas-somewhat reminiscent of the path cyclones over the North Atlantic that take on their more northerly route - indicate that the existence of Greenland guarentees warmer temperatures in this region than

\section{b) $\mathrm{T} 106 \mathrm{~T}$ on $500 \mathrm{hPa}$}
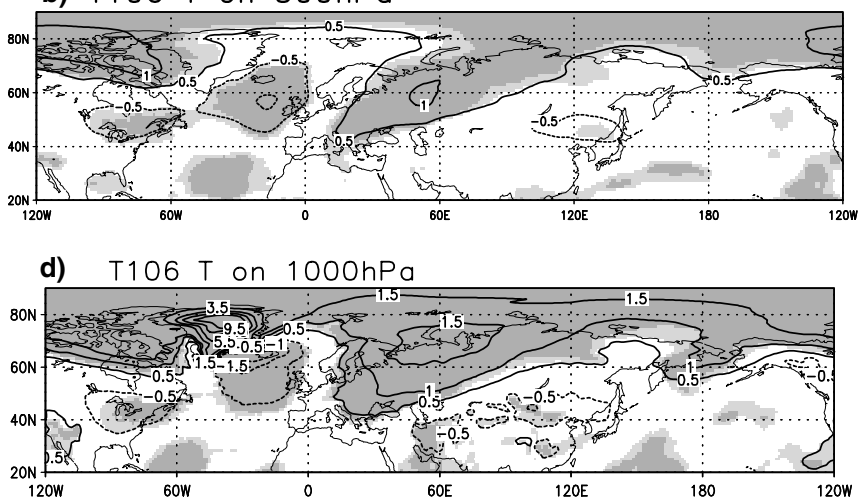

line drawn; Contour levels in (c, d): $-1.5,-1 .,-0.5,0.5,1 ., 1.5,3.5$, 5.5, 7.5, 9.5. Dark shading indicates 0.05 significance level, light shading 0.1 significance level 
would be there otherwise. This feature is qualitatively similar over the entire column of the troposphere (Fig.5a, b shows temperature anomalies at $500 \mathrm{hPa}$ for illustration). It is interesting to note that the effects are of the same sign in the eastern United States and over the Atlantic and the most of the western parts of Europe. Hence, there is no net effect on the climate contrast between western European and North American winters, unlike findings by Seager et al. (2002), who investigated the role of the Rocky Mountains in that contrast. These temperature changes mimic the change in dynamic height of the pressure surfaces, i.e. its thickness, throughout the lower and middle troposphere (not shown).

\subsection{Far-field response}

Consistency between the two model resolutions is not found for the remainder of the northern hemisphere. The response pattern of the stationary wave field appears to be hemispheric in both cases, but the characteristics of the far-field patterns turn out to be quite different. In the lower resolution, we see a rather uniform response over the remainder of the mid-latitude and polar latitudes (Fig. 5a), i.e. increased geopotential heights with local maxima over the Black Sea region, Mongolia and most of the northeastern parts of Asia, close to the Bering strait. In two of these centres, the changes are statistically significant at the $5 \%$ level, but for major parts of the Eurasian and Pacific sector, the changes are rather small. The shading indicating wavelike significance in the tropical belt is due to the fact that variability there is minimal in the CTRL integrations, a consequence of the absence of ENSO-type variability in the climatological SSTs used to drive the atmospheric model.

Hemispheric-wide, temperature changes in the T42 resolution closely match the changes in the stationary wave field. Figure 5(a,c) demonstrates a warming in the region spanning almost the entire Eurasian continent north of $40^{\circ} \mathrm{N}$. In contrast to the rather uniform far-field response pattern in the low resolution, the changes in the T106 resolution might be interpreted as indicative of wave propagation beyond the Atlantic sector north of $40^{\circ} \mathrm{N}$ (Fig. 5b). This suggests a weak wavenumber-two pattern in the polar latitudes at $500 \mathrm{hPa}$, with amplitude attenuation though. Concomitantly, the far-field patterns of temperature changes do not match those of the lower resolution. An extended region of warming over Eurasia in the NOGREEN case is also present, but its extension is more confined to the inner continent. It also shows a clear connection to the warming over the entire Northern Canada region.

To summarize, changes in the orographic height in the Greenland area cause changes in the climatological stationary wave field, of large amplitude in the wider surroundings of Greenland, and lower amplitudes in the far-field response. Temperature responses are in geo- strophic equilibrium with the geopotential height field changes. A test to evaluate if the differences in the farfield response of the different model resolutions are significant reveals that at a significance level of 0.05 , that is the case over major parts of Eurasia (not shown). We also considered changes in the transient eddy-heat flux, in order to evaluate whether the transients are causal in the creation of these temperature changes. However, changes of transient eddy-heat flux from CTRL to NOGREEN can only partly explain the temperature changes we see, and the results remain inconclusive. The interesting question now is whether changes in the climatological fields induce changes in the space-time characteristics of their variability.

\section{Teleconnections and storm tracks}

\subsection{Teleconnections}

The term teleconnection pattern refers to a recurring and persistent large-scale pattern of pressure and circulation anomalies occupying a large area of the globe. The concept was introduced by Wallace and Gutzler (1981). In the following, we discuss the manifestation of teleconnections in the surface pressure field.

Figure 6 contains the leading teleconnection pattern of SLP for the northern hemisphere north of $20^{\circ} \mathrm{N}$ in the model integrations (i.e. 1.EOFs calculated from seasonal SLP fields). In the CTRL run of the T42 resolution, the teleconnection pattern (Fig. 6a) shows high correlations in the Pacific along a zonal band between $30^{\circ} \mathrm{N}$ and $50^{\circ} \mathrm{N}$, over the entire Arctic region, with the centre of action sitting near South Greenland, and in the North Atlantic/European sector between $35^{\circ} \mathrm{N}$ and $55^{\circ} \mathrm{N}$. In the latter two regions, this pattern compares well with the observations (see for example Ambaum et al. (2001); Thompson and Wallace (2000)).

In the T106 model, the displacement of the mean pressure field, discussed in Sect. 2, apparently has some repercussions for the teleconnections produced by that model (Fig. 6b). Its polar centre is situated as far east as the Barents Sea, with its southern counterpart over the North Atlantic, occupying the area over mainland Spain instead of the Azores. The latter is rather weak, as is its Pacific counterpart.

The regional manifestation of those patterns in the Atlantic/European sector shows the structure and characteristics of the most important mode of variation in this region seen in observations, the North Atlantic Oscillation (see Marshall et al. 2001 for a recent review). The particular method used to determine this map, or even the region selected, which sometimes is a critical parameter for some methods, prove irrelevant to the location of centres of action (not shown).

The teleconnection maps of the NOGREEN experiments (Fig.6c, d) show the same overall structure as in the CTRL integration. The dominant dipolar mode over the North Atlantic remains the leading pattern of vari- 
Fig. 6 Leading empirical orthogonal function of SLP in DJF, computed from seasonal means a T42 resolution CTRL (67\% of variance), b T106 resolution CTRL (54\%), c T42 resolution NOGREEN $(52 \%)$, and $\mathbf{d}$ T106 resolution NOGREEN $(42 \%)$ a) T42 CONTROL

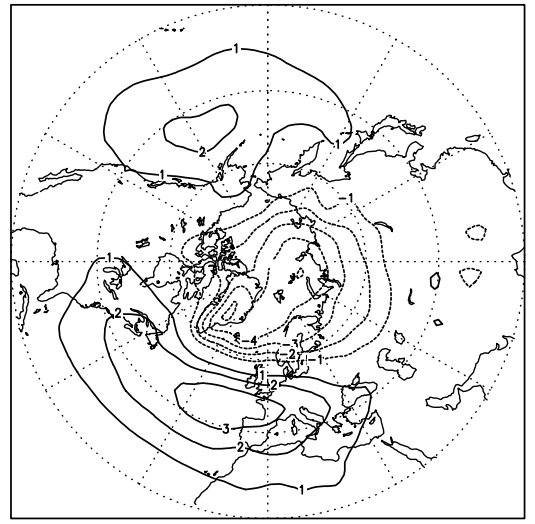

c) T42 NOGREEN

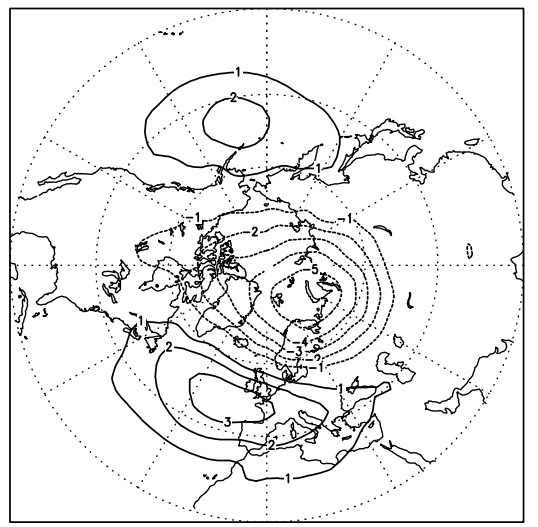

b) T106 CONTROL

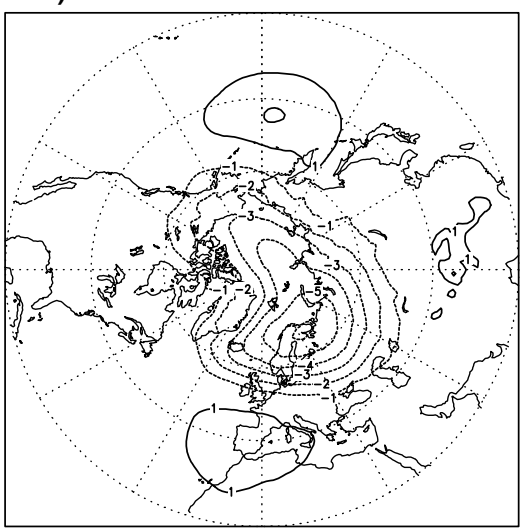

d) T106 NOGREEN

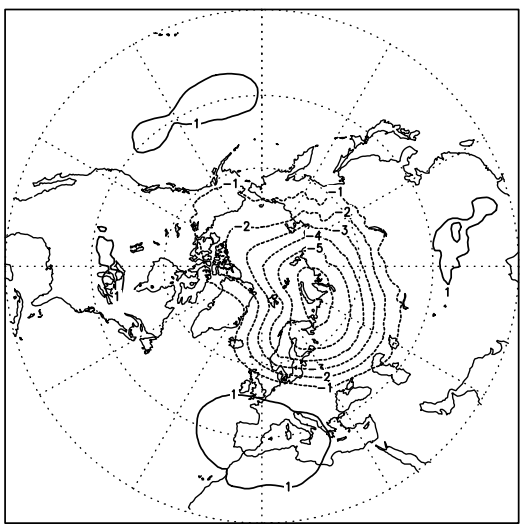

ability in the Atlantic/European sector; with the somewhat reduced variance it accounts for in both resolutions. However, there are some noticeable differences.

The existence of the Greenland mountain seems to influence the particular location of centres of action of the NAO. In the low-resolution experiment (Fig.6c), the northern centre is shifted northeast when Greenland is removed, now occupying the Barents Sea and even the Kara Sea, with the consequence that the associated winds are stronger over the northwestern Eurasian area.

Similarly, in the high-resolution case (Fig.6d), we see a shift of the northern centre of action of the pattern in the eastern Arctic region. The northern antipode occupies a larger area extending from northern Scandinavia to the eastern flank of the Kara Sea, sitting further downstream, from a Greenland point of view. However, the climatological SLP fields rather show a general decrease in pressure over the northern parts of the North Atlantic and Eurasia, north of $60^{\circ} \mathrm{N}$, not a systematic shift. This suggests that the manifestation of the NAO centres is not necessarily linked mechanistically to the climatological high- and low-pressure systems in the North Atlantic.

The integrations are too short to derive strong statements about changes in variability on the interannual or longer time scales. We have attempted to get indications whether we can expect changes in frequency distributions by using daily indices of the NAO index, defined as projection of daily SLP fields on to the NAO pattern of the CTRL integrations (Atlantic/European sector of Fig.6a, b). The results do not indicate any significant shifts in these distributions, for either model resolution. Using the NOGREEN NAO pattern for the projection of NOGREEN SLP data does not change these results.

\subsection{Storm tracks}

The NAO mode has been associated with the path and the strength of the North Atlantic storm-track (Lau 1988; Rogers 1997, 1990). Without dwelling at this point on the discussion, whether the mean circulation determines the path of the synoptic systems or if the transients determine the mean as a statistical parameter, we investigate possible changes in intensity and tracks of the synoptic systems, employing two different approaches: cyclone-track determination (Lagrangian approach) and standard deviation of band-pass filtered geopotential height (Eulerian approach).

Individual cyclone tracks are inferred from local pressure fields. Figure 7 shows the cyclone density derived from individual cyclones that pass the North Atlantic region, using the procedure developed by Blender et al. (1997). The quantity expresses the probability of encountering a cyclone at any particular time 
Fig. 7 Cyclone occupation (times 100) per $(1,000 \mathrm{~km})^{2}$ at an "observation time": a T42 resolution CTRL, b T106 resolution CTRL, c T42 resolution NOGREEN and d T106 resolution NOGREEN; Contour interval 5, thick lines 15 and 20 contour lines a) T42 CTRL

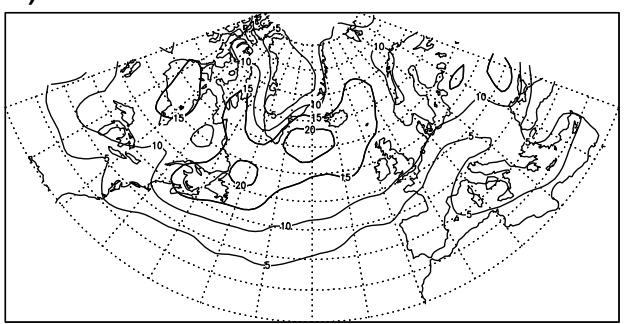

c) T42 NOGREEN

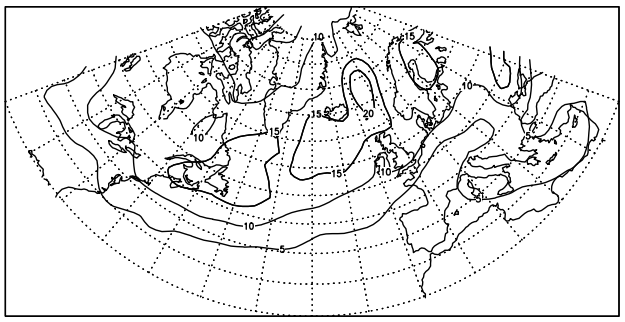

b) T106 CTRL

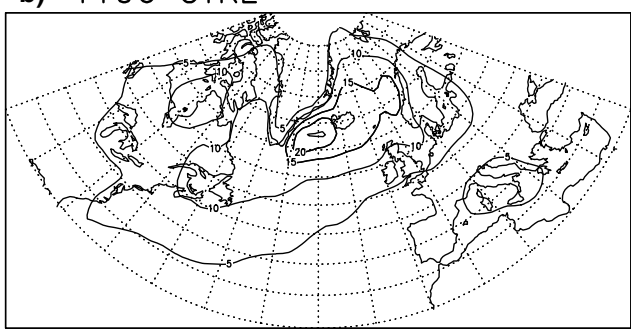

d) T106 NOGREEN

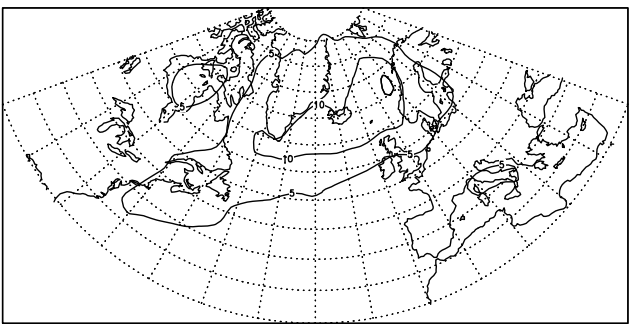

in the designated area of $1,000^{2} \mathrm{~km}^{2}$. In both, low- and high-resolution integrations, a maximum band straddles the North Atlantic from the North American coast around Nova Scotia to the western coast of Norway. Maximum probability is detected in the lee of the South Greenland tip. An intrusion of cyclones into the Labrador Sea and Baffin Bay is apparent in both resolutions. A secondary maximum is present over the Mediterranean. The maxima and overall structure as derived from observations by Sickmöller et al. (2000) are captured well by the model, even in quantitative terms.

The primary changes in both resolutions (Fig. 7c, d) are (1) more cyclones pass over the flat-bottom Greenland area, (2) there are less cyclones in the east of the southern tip of Greenland, suggesting that cyclones in these areas are primarily generated locally through vortex stretching. While we find a mere decrease of these cyclones in the high-resolution model, in the low-resolution, this high probability region appears to be shifted eastward with the maximum now east of Iceland. And (3) the intrusion tongue into the Labrador sea has vanished.

Qualitatively similar, the standard deviation of the $500 \mathrm{hPa}$ geopotential height in the 2.5-8 days band (Fig. 8) reveals the North Atlantic storm track in the northern hemisphere winter. The maximum variance of the North Atlantic storm track is located around New Foundland, at the southern edge of the Labrador Sea, in both control integrations, which is in accordance with the same diagnostics as derived from the ERA15 dataset (not shown). The stormtrack extends well into northern and central Europe and this is represented realistically in
Fig. 8 Standard deviation of geopotential height at $500 \mathrm{hPa}$ in the band-pass filtered frequency range (2.5-8 days): a DJF climatology T42 resolution and $\mathbf{b}$ DJF climatology T106 resolution with contour interval $10 \mathrm{~m}$; change from CTRL to NOGREEN experiments in c T42 resolution and d T106 resolution with contour interval $2 \mathrm{~m}$, no zero line drawn. Dark shading indicates 0.05 significance level, light shading 0.1 significance level a) T42 CTRL

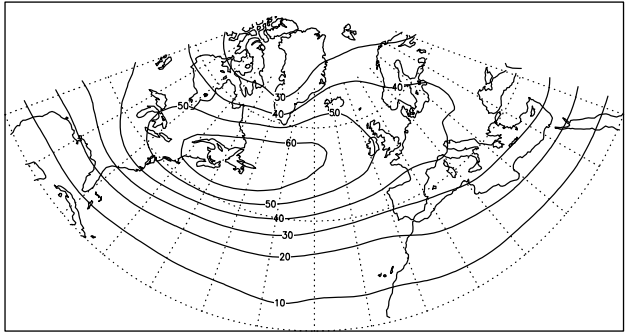

c) T42 NOGREEN-CTRL

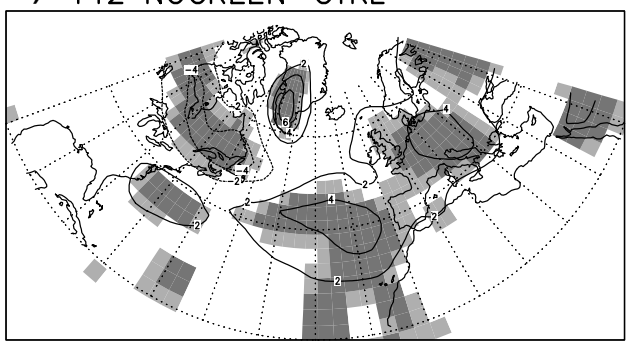

b) T106 CTRL

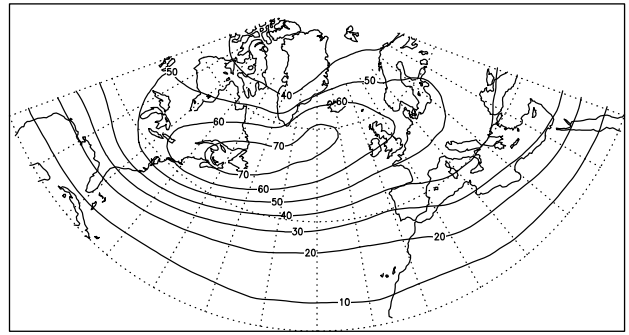

d) T106 NOGREEN-CTRL

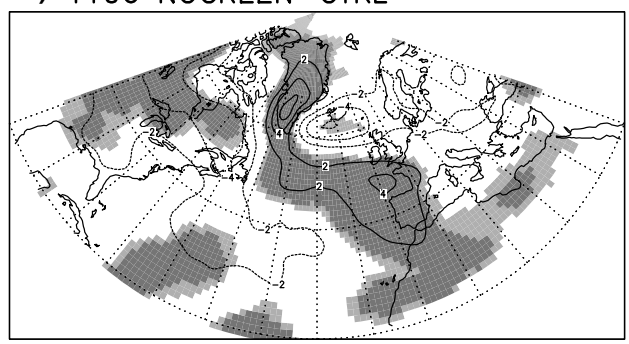


the T42 model. The analysis of the T106 results indicates an overestimation of storm-track activity over Europe. Recalling the eastward displacement of the mean lowpressure system, and the associated changes of the strongest pressure gradients that provide an indication of (1) strong winds and (2) possible instabilities, this storm-track extension appears to be physically consistent within the model.

Figure $8 \mathrm{c}, \mathrm{d}$ illustrates the changes in storm-track activity. Increase of storm-track activity takes place in the southern half of Greenland, in the high-pressure area around the Azores and, for the T42 resolution, along the southern flank of the climatological stormtrack into Europe. The increase over southern Greenland accounts for roughly $20 \%$ of the variance and is consistent with an increase of cyclone activity in this area (compare Fig. 8c, d). The storm-track activity decreases over Canada and, for the T106 resolution, the Nordic seas between Greenland and Scandinavia. For the latter, the decrease occurs in the area of cyclone activity decrease (cmp. Fig 8d).

The differences between the Lagrangian and Eulerian diagnostics have, at least, two sources. Only low-pressure systems are considered in the cyclone statistic and both the pressure gradient and duration have to surpass a certain threshold. Apart from that, their duration is unlimited. In the Eulerian approach, only a particular frequency band is considered. Also, high- and lowpressure systems enter the calculations. Low-pressure systems usually take a more northerly track than highpressure systems and this is reflected in the different patterns (Figs. 7 and 8, respectively).

\section{Summary and discussion}

The orographic forcing role of Greenland's glacier mountain has drawn new attention as trends indicate a warming of the Arctic (Gregory et al. 2004) and associated lengthening of the melting season. Several authors have cautioned about the potential irreversibility of the disappearance of the Greenland icesheet (Crowley and Baum 1995; Toniazzo et al. 2004). However, we focus here on investigating the effect of the Greenland orography on northern hemisphere winter circulation and teleconnection patterns - and how these would change in the case of a flat-bottom Greenland. We have conducted experiments of the ECHAM4 atmospheric model with two different resolutions and found significant changes from CONTROL to NOGREEN integrations in both model resolutions, but the response patterns are not consistent in all regions of the northern hemisphere.

One of the results of this study is that in a world without Greenland's mountains the stationary wave field would be weaker over a fairly large region of the northern hemisphere, according to the model experiments. In the vicinity of the forcing, the changes appear to be consistent between the different model resolutions. Both the climatological trough over eastern Canada and the climatological ridge over the eastern Atlantic are weakened. Hence, the Greenland orography reinforces stationary waves in that area, excited in the Rocky Mountain area. Though this result was already indicated by Hoskins and Karoly (1981), the changes cannot be understood in the framework of stationary Rossby waves. Instead, with Greenland orography, low-level air to the west is blocked by the mountain, cooled persistently in winter, and hence, geopotential heights decrease. This reasoning is quite similar to the findings of Petersen et al. (2004) in experiments with the NCAR Community climate model CCM3 in a T106 resolution, which show that Greenland has a damming effect on the air masses on its western side, which is cooled by radiative heat loss during winter, leading to less geopotential thickness in the area and thus less $500 \mathrm{hPa}$ geopotential than in the case without Greenland.

Apart from this rather local effect, both resolutions suggest almost hemispheric, far-field changes. In contrast to the former, the latter display resolution-dependent spatial patterns, which prove significant in their respective centres of action. The T42 response (Fig. 5a) is rather uniform with increased geopotential heights in the mid-latitude region, while the T106 response indicates a wavenumber-two propagation in the polar area. The difference in this resolution-dependent responses is significant over most parts of Eurasia.

Hemispheric changes of tropospheric temperature from CTRL to NOGREEN integrations indicate a warming over northern parts of the Eurasian continent, more extended though in the low resolution case, while the North Atlantic undergoes a cooling.

However, Toniazzo et al. (2004) in experiments with the HadCM3 investigating the possible irreversibility of a Greenland deglaciation, in their model find that when only the Greenland icesheet is removed, this does not have a noticeable climate influence farther afield.

One interesting result evident in both resolutions is that the northern centre of action of the regional (NAO) or hemispheric (AO) mode of variation undergoes a substantial shift in an easterly direction. Though their positions are quite different in the respective CTRL integrations, in both NOGREEN experiments, the centre of action is found approximately over Nova Zemlja. This is particularly noticeable as the SLP field itself shows no remarkable shift of the mid-latitude low- and high-pressure systems, just a decrease in the pressure in Arctic areas of the North Atlantic and Eurasia, the implication being that it appears to be happenstance that the centres of action of the main regional mode of variation over the North Atlantic coincide with the climatological low- and high-pressure centres of that area. A caveat, however, in the Petersen et al. (2004) paper, the same analysis reveals no major changes in the centres of action from CTRL to NOGREEN.

It is important to emphasize that we have no means to decide which of the two model resolutions gives the more relevant or realistic answer, if any, to the posed question. For the near-field or local response, the 
changes due to altered orography prove rather insensitive to model resolution, the implication being that $\mathrm{T} 42$ sufficiently resolves the relevant processes for this particular problem. On the hemispheric scale, however, the results do suggest a resolution-dependency. Recalling that the T42 model produces a more realistic climatology as seen in the SLP field and the diagnostic teleconnection pattern, we might tend to argue that the differences in the NOGREEN experiment are also more realistic. On the other hand, Merkel and Latif (2002) show that transient eddy processes are captured adequately only in the T106 resolution and whether they play a role in the response found here, is not clear.

Also, the comparison with the study by Petersen et al. (2004) does not provide guidance in this respect as their model experiments were only calculated for one resolution, namely T106, of the CCM3 model. Their results, for example in the $500-\mathrm{hPa}$ height response, are again similar to ours in the local response, but show a different pattern in the far-field response (their Fig. 5b), rather matching the T42 pattern of the ECHAM4 experiments (see Fig. 5a) than the T106 pattern. It is interesting to note that the climatological SLP field of the T106 CCM3 model exhibits the same deficiency as the ECHAM4 T106 with respect to the position of the low-pressure system over the North Atlantic (their Fig. 2a).

In contrast to Dong and Valdes (2000), who suggested that the differences in model climatology are rather quantitative beyond T42 wave-number truncation, we find indications that the response can also vary qualitatively beyond this resolution. However, they also find that even the resolution dependency may depend on the climatic state.

Thus, modelling the mean circulation correctly, not only in a zonal mean sense, is not only an important issue in itself. It is always difficult to judge how far the results on sensitivity and variability can be trusted if we have no confidence in the processes that shape the model climatology. Whether the mean state is realized as a statistical result of synoptic, high frequency fluctuations, or the transients are steered by the mean background setting, the mean state is vital in shaping spatial and temporal scales of variability.

Acknowledgements We are greatly indebted to the Model and Data group, Hamburg, for providing the reanalysis data $(\mathrm{ECMWF} /$ DWD/DKRZ: 1996). We would like to thank the two anonymous reviewers for their constructive suggestions and comments on the manuscript. They helped to improve the presentation of our results. We thank Rita Seiffert for providing the cyclone-track statistics. This work was funded by the Deutsche Forschungsgemeinschaft (DFG) within the Sonderforschungsbereich 512: Tiefdruckgebiete und Klimasystem des Nordatlantiks.

\section{References}

Ambaum MHP, Hoskins BJ, Stephenson DB (2001) Arctic Oscillation or North Atlantic Oscillation. J Climate 14:3495-3507
Bacher A, Oberhuber JM, Roeckner E (1998) ENSO dynamics and seasonal cycle in the tropical Pacific as simulated by the ECHAM4 / OPYC3 coupled general circulation model. Clim Dyn $14: 431-450$

Blender R, Fraedrich K, Lunkeit F (1997) Identification of cyclone track regimes in the North Atlantic. Quart J R Met Soc 123:727-741

Charney J, Eliassen A (1949) A numerical model for prediciting the perturbations of the middle latitude westerlies Tellus 1:38-54

Christoph M, Ulbrich U, Oberhuber JM, Roeckner E (2000) The Role of Ocean Dynamics for Low-Frequency Fluctuations of the NAO in a Coupled Ocean-Atmosphere GCM. J Climate 13:2536-2549

Crowley TJ, Baum SK (1995) Is the Greenland Ice Sheet bistable?. Paleoceanography 10:357-363

Dong B, Valdes PJ (2000) Climates at the Last Glacial Maximum: Influence of Model Horizontal Resolution. J Climate 13:1554 1573

Gregory JM, Huybrechts P, Raper SCB (2004) Threatened loss of the Greenland ice-sheet. Nature 428:616

Held IM (1983) Stationary and quasi-stationary eddies in the extratropical troposphere. In: Hoskins BJ, Pearce DP (eds) Large-Scale dynamical processes in the atmosphere. Academic Press, London pp 127-168

Hoskins B, Karoly DJ (1981) The steady linear response of a spherical atmosphere to thermal and orographic forcing. J Atmos Sci 38:1179-1196

Kristjánsson JE, McInnes H (1999) The impact of Greenland on cyclone evolution in the North Atlantic. Quart J R Met Soc 125:2819-2834

Lau N (1988) Variability of the observed midlatitude storm tracks in relation to low-frequency changes in the circulation pattern. J Atmos Sci 45:2718-2743

Marshall J, Kushnir Y, Battisti D, Chang P, Czaja A, Dickson R, Hurrell J, McCartney M, Saravanan R, Visbeck M (2001) North Atlantic climate variability: phenomena, impacts and mechanisms. Int J Climat 21:1863-1898

May W (2001) Impact of horizontal resolution on the simulation of seasonal climate in the Atlantic/European area for present and future times. Climate Research 16:203-223

Merkel U, Latif M (2002) A High Resolution AGCM Study of the El Niño Impact on the North Atlantic/European Sector. Geophys Res Lett 29:10.1029

Petersen GN, Kristjánsson JE, Olafsson H (2004) Greenland and the northern hemisphere winter circulation. Tellus A 56:102111

Plumb RA (1985) On the three-dimensional propagation of stationary waves. J Atmos Sci 42:217-229

Ringler TD, Cook KH (1995) Orographically induced stationary waves: dependence on latitude. J Atmos Sci 52:2548-2560

Roeckner E, Arpe K, Bengtsson L, Christoph M, Claussen M, Dümenil L, Esch M, Giorgetta M, Schlese U, Schulzweida U (1996) The atmospheric general circulation model ECHAM-4 Tech rep. Max-Planck-Institut für Meteorologie, Hamburg

Rogers JC (1990) Patterns of low-frequency monthly sea level pressure variability (1899-1986) and associated wave cyclone frequencies. J Climate 3:1364-1379

Rogers JC (1997) North Atlantic storm track variability and its association to the North Atlantic Oscillation and climate variability of northern Europe. J Climate 10:1635-1647

Schwierz CB (2001) Interactions of Greenland-scale orography and extra-tropical synoptic-scale flow Tech rep. Swiss Federal Institute of Technology, Zurich, Switzerland

Seager R, Battisti DS, Yin J, Gordon N, Naik N, Clement AC, Cane MA (2002) Is the Gulf Stream responsible for Europe's mild winters?. Quart J R Met Soc 128:2569-2586

Sickmöller M, Blender R, Fraedrich K (2000) Observed winter cyclone tracks in the northern hemisphere in re-analysed ECMWF data. Quart J R Met Soc 126:591-620

Thompson DWJ, Wallace JM (2000) Annular modes in the extratropical circulation Part I: month-to-month variability. J Climate 13:1000-1016 
Toniazzo T, Gregory JM, Huybrechts P (2004) Climatic Impact of a Greenland Deglaciation and Its Possible Irreversibility. J Climate 17:21-33

Ulbrich U, Christoph M (1999) A shift of the NAO and increasing storm track activity over Europe due to anthropogenic greenhouse gas forcing. Clim Dyn 15:551-559
Wallace M, Gutzler G (1981) Teleconnections in the geopotential height field during the northern hemisphere winter. Mon Weath Rev 109:784-128 